\title{
Lifestyle Analysis of Infertile Couples at a Rural Hospital - Review Over Twenty Years
}

\author{
Samal Swarnlata L, Karpate Shilpaja J, Dhadwe Kanchan, \\ Dept. of Obs /Gyn, \\ Mahatma Gandhi Institute of Medical Sciences, \\ Sevagram, Wardha, Maharashtra, India.
}

\begin{abstract}
Aim: To evaluate the lifestyle of 3000 infertility rural couples.

Methods: Settings and design: Department of Obstetrics and Gynecology in a rural hospital, eastern Maharashtra, Sevagram near Ward. Lifestyle of 3000 infertile rural couples was analyzed. Statistical analysis was done by EPI-6 software, Chi square test

Result: The prevalence of infertility increased from $8.97 \%$ (269) to $14.63 \%$ (439) over the last two decades. Primary infertility was present in $1860(62.00 \%)$ cases. Majority of the cases, $1226(40.87 \%)$ were in the age group 26-30 years and the median age was 27.25 years. Couples seeking treatment has increased in both Hindus and Muslim community over the years but it has remained nearly the same for Christians. The prevalence of infertility was found to be higher 1950(65.00\%) in men and in women 1800(60.00\%) who were farmers or laborers. Cases from joint families had higher 2220(74.00\%) prevalence of infertility. The prevalence of infertility was higher $2018(67.27 \%)$ in cases taking the mixed diet as compared to those taking a vegetarian meal 982(32.73\%). Highest numbers of cases were from lower socioeconomic group with the overall prevalence being 1860 (62\%) cases 2333. (77.77\%) of infertile males were addicted to alcohol or smoking.
\end{abstract}

Conclusion: Modification in lifestyle factors may improve fertility rates. Physician must be aware of these risks and counsel the couples accordingly. Further studies are required to prove the factors beyond doubt.

Keywords: Infertility, rural hospital, lifestyle

\section{Introduction}

Since the beginning of time human infertility has been a source of personal misery. The Egyptians, Greeks and earlier civilizations all had empirical treatments - love potions, amulets, prayers and sacrifices for curing it.

Infertility is defined as inability to conceive for a year despite regular and unprotected intercourse. Chang et al $(2005)^{1} \quad$ stated that the goals of the infertility evaluation are to determine the etiology of infertility in an expedient fashion, to define appropriate treatment protocols and to predict realistic success rates to educate the couple on their infertility etiologies. Primary diagnostic evaluation represents the first line testing. In our study we have analyzed the trends and epidemiological factors in the rural institute situated in the eastern part of Maharashtra, over a period of 20 years (Aug 1987 to July 2007) with an aim to find out the impact of lifestyle on fertility and to suggest modifications of these risk factors.

\section{Methods}

The present study is a non-intervention observational study that comprised retrospective review of lifestyle of infertility cases over a period of 20 years (Aug 1987 to July 2007) in our department in eastern Maharashtra a place called Sevagram which is near Ward. The study period was divided into five blocks, Block A (Aug1987- July 1991), Block B (Aug1991 - July1995), Block C (Aug 1995- July1999), Block D (Aug 1999July 2003) and Block E (Aug 2003-July 2007). 
For the study we manually collected the case records of women from the medical records department from history sheets. All records were entered on a self-coded form consisting of analyzed variables as described and care was taken to ensure protection of health information

Analysis of the records was done in relation to the age of female at presentation, age at marriage, type of infertility, religion, occupation, socio-economic status, type of family, dietary factors, addiction.

Statistical analysis was done using EPI-6 software and the Chi square test.

\section{Results}

During the 20 year period, the total number of gynecological admissions was 25670, of which $3000(11.69 \%)$ were cases of infertility. The prevalence varied from $8.97 \%$ (269) to $14.63 \%$ (439) over the last two decades. $74.20 \%$ (2226) cases were from the rural habitation and $25.8 \%$ (774) were from urban areas. The distribution according to the type of infertility was -
Primary infertility --- 1860(62.00\%)

Secondary infertility --- 1140 (38.00\%)

The youngest female was of 19 years and the oldest was 40 years, the median age being 27.25 years. Maximum number of infertile couple presented in the age group of 26- 30 years, 1226(40.87\%). Analysis of the cases in relation to age at the time of marriage has shown that $468(15.60 \%)$ got married between 16 to 20 years, $1246(41.53 \%)$ between 21 to 25 years, 940 (31.33\%) between 26 to 30 years and $346(11.53 \%)$ were $>30$ years.

The prevalence of infertility is in increasing order in all the religious groups. More Hindus have enrolled for treatment, 1980(66\%), compared to other religions $1020(34 \%)$ cases. While the number of couples seeking treatment has increased in both Hindus and Muslim community over the years, it has remained the same for Christians; 35 (1.17\%), 51 (1.7\%), 48 (1.6\%), 50 $(1.67 \%)$ and $56(1.87 \%)$ respectively in block $\mathrm{A}, \mathrm{B}, \mathrm{C}$, $\mathrm{D}$ and $\mathrm{E}$ respectively. (Table1)

\section{Table 1. Distribution according to religion of females}

\begin{tabular}{ccccc}
\hline BLOCK* & HINDU(\%) & MUSLIM(\%) & OTHER(\%) & TOTAL(\%) \\
\hline A & 299 & 96 & 35 & 430 \\
& $(9.97)$ & $(3.2)$ & $(1.17)$ & $(14.33)$ \\
B & 348 & 126 & 51 & 525 \\
& $(11.6)$ & $(4.2)$ & $(1.7)$ & $(17.5)$ \\
$\mathrm{C}$ & 408 & 144 & 48 & 600 \\
& $(13.6)$ & $(4.8)$ & $(1.6)$ & $(20.00)$ \\
$\mathrm{D}$ & 450 & 160 & $(1.67)$ & 660 \\
& $(15)$ & $(5.33)$ & 56 & $(22.00)$ \\
$\mathrm{E}$ & 475 & 254 & $(1.87)$ & 785 \\
& $(15.83)$ & $(8.47)$ & 240 & $(26.17)$ \\
\hline Total & 1980 & 780 & $(8.00)$ & 3000 \\
& $(66.00)$ & $(26.00)$ & \\
\hline
\end{tabular}

*Block A: Aug 1987- July 1991; Block B Aug1991 - July1995 ; Block C Aug 1995- July1999;

Block D Aug 1999-July 2003 and Block E Aug 2003-July 2007.

Table 2. Distribution according to occupation of females

\begin{tabular}{ccccc}
\hline BLOCK & $\begin{array}{c}\text { FARM } \\
\text { WORKER/LABORERS } \\
(\%)\end{array}$ & $\begin{array}{c}\text { HOUSE WIVES } \\
(\%)\end{array}$ & $\begin{array}{c}\text { SEDENTARY JOB } \\
(\%)\end{array}$ & $\begin{array}{c}\text { TOTAL } \\
(\%)\end{array}$ \\
\hline A & 172 & 170 & 88 & 430 \\
& $(5.73)$ & $(5.67)$ & $(2.93)$ & $(14.33)$ \\
B & 368 & 61 & 96 & 525 \\
& $(12.27)$ & $(2.03)$ & $(3.2)$ & $(17.5)$ \\
C & 380 & 118 & 102 & 600 \\
& $(12.67)$ & $(3.93)$ & $(3.4)$ & 660 \\
D & 400 & 156 & $(3.47)$ & $(22)$ \\
& $(13.33)$ & $(5.2)$ & 90 & 785 \\
E & 480 & 215 & $(3)$ & $(26.17)$ \\
\hline Total & $(16)$ & $(7.17)$ & 480 & $(16)$ \\
& 1800 & $(24)$ & $(100)$ \\
\hline
\end{tabular}

*Block A: Aug 1987- July 1991; Block B Aug1991 - July1995 ; Block C Aug 1995- July1999;

Block D Aug 1999-July 2003 and Block E Aug 2003-July 2007. 
The maximum cases are from male partners who are farm workers or laborers 1950(65\%) compared to factory workers $870(29 \%)$ and those involved in sedentary job $180(6 \%)$. Similar trend was true for females also, with $1800(60 \%)$ being farm workers or laborers, $720(24 \%)$ housewives and $480(16 \%)$ involved in sedentary job. (Table $2 \& 3$ ).
The distribution of cases depending on the diet is shown in the (Table 4 ) where the majority $2018(67.27 \%$ ) were taking mixed diet and minority 982(32.73\%) were vegetarian. Those taking non vegetarian diet have increased in the past twenty years; from 175 (5.83\%) in block A to $589(19.53 \%)$ in $\mathrm{E}$.

Table 3. Distribution according to occupation of males

\begin{tabular}{ccccc}
\hline BLOCK* & $\begin{array}{c}\text { FARM WORKER } \\
\text { /LABORERS(\%) }\end{array}$ & $\begin{array}{c}\text { FACTORY } \\
\text { WORKERS (\%) }\end{array}$ & $\begin{array}{c}\text { SEDENTARY } \\
\text { JOB(\%) }\end{array}$ & $\begin{array}{c}\text { TOTAL } \\
(\%)\end{array}$ \\
\hline A & 300 & 103 & 27 & 430 \\
& $(10)$ & $(3.43)$ & $(0.9)$ & $(14.33)$ \\
B & 325 & 166 & 34 & 525 \\
& $(10.83)$ & $(5.53)$ & $(1.13)$ & $(17.5)$ \\
C & 415 & 146 & 39 & 600 \\
& $(13.83)$ & $(4.87)$ & $(1.3)$ & $(20)$ \\
D & 445 & 179 & 36 & 660 \\
& $(14.83)$ & $(5.97)$ & $(1.2)$ & $(22)$ \\
E & 465 & 276 & 44 & 785 \\
& $(15.5)$ & $(9.2)$ & $(1.47)$ & $(26.17)$ \\
\hline Total & 1950 & 870 & 180 & 3000 \\
& $(65.00)$ & $(29.00)$ & $(6.00)$ & $(100)$ \\
\hline
\end{tabular}

*Block A: Aug 1987- July 1991; Block B Aug1991 - July1995 ; Block C Aug 1995- July1999;

Block D Aug 1999-July 2003 and Block E Aug 2003-July 2007.

Table 4. Distribution according to dietary habits

\begin{tabular}{cccc}
\hline BLOCK & $\begin{array}{c}\text { VEGETARIAN } \\
\text { DIET(\%) }\end{array}$ & MIXED DIET(\%) & TOTAL(\%) \\
\hline $\mathrm{A}$ & 255 & 175 & 430 \\
& $(8.5)$ & $(5.83)$ & $(14.33)$ \\
$\mathrm{B}$ & 169 & 356 & 525 \\
& $(5.63)$ & $(11.87)$ & $(17.50)$ \\
$\mathrm{C}$ & 142 & 458 & 600 \\
& $(4.73)$ & $(15.27)$ & $(20.00)$ \\
$\mathrm{D}$ & 220 & 440 & 660 \\
& $(7.33)$ & $(14.67)$ & $(22.00)$ \\
$\mathrm{E}$ & 196 & 589 & 785 \\
& $(6.53)$ & $(19.53)$ & $(26.17)$ \\
\hline Total & 982 & 2018 & 3000 \\
& $(32.73)$ & $(67.27)$ & $(100.00)$ \\
\hline
\end{tabular}

*Block A: Aug 1987- July 1991; Block B Aug1991 - July1995 ; Block C Aug 1995- July1999;

Block D Aug 1999-July 2003 and Block E Aug 2003-July 2007.

Table 5. Distribution according to type of family

\begin{tabular}{cccc}
\hline BLOCK & NUCLEAR(\%) & JOINT(\%) & TOTAL(\%) \\
\hline $\mathrm{A}$ & 129 & 301 & 430 \\
& $(4.3)$ & $(10.03)$ & $(14.33)$ \\
$\mathrm{B}$ & 219 & 306 & 525 \\
& $(7.3)$ & $(10.2)$ & $(17.5)$ \\
$\mathrm{C}$ & 92 & 508 & 600 \\
& $(3.07)$ & $(16.93)$ & $(20.00)$ \\
$\mathrm{D}$ & 115 & 545 & 660 \\
& $(8.83)$ & $(18.17)$ & $(22.00)$ \\
$\mathrm{E}$ & 225 & 560 & 785 \\
& $(7.5)$ & $(18.67)$ & $(26.17)$ \\
\hline Total & 780 & 2220 & 3000 \\
& $(26.00)$ & $(74.00)$ & $(100)$ \\
\hline
\end{tabular}

*Block A: Aug 1987- July 1991; Block B Aug1991 - July1995 ; Block C Aug 1995- July1999;

Block D Aug 1999-July 2003 and Block E Aug 2003-July 2007. 
Table 5 shows that $780(26.00 \%)$ cases belonged to nuclear family and $2220(74.00 \%)$ cases were living in a joint family. The percentage of nuclear family has increased in last 5 years 225(7.5\%) compared to $129(4.3 \%)$ in Block A. But staying in the joint family still is the way of life in rural India. [560(18.67\%) in block E and 545(18.17\%) in block D].

In our study each year highest number of cases were from lower socioeconomic group with the overall prevalence being $1860(62 \%)$ cases and $342(11.4 \%)$, $426(14.2 \%), 204(6.8 \%)$ and $168(5.6 \%)$ belonging to lower middle, middle, high middle, high socioeconomic groups respectively. (fig 1)

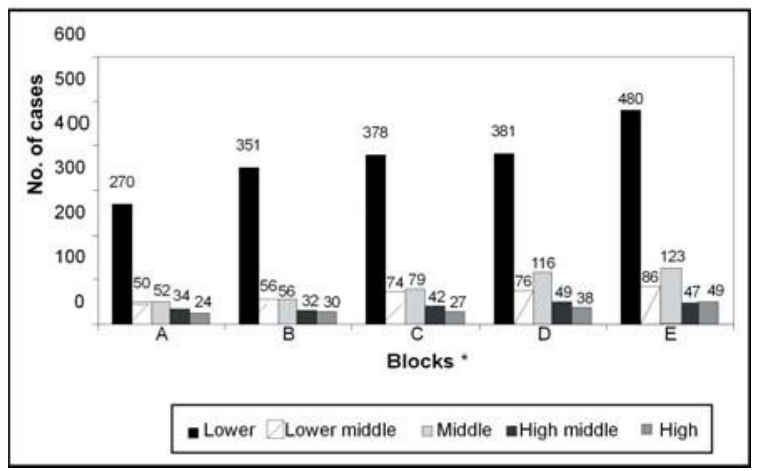

Fig 1. Block wise distribution of cases in relation to Socioeconomic status

*Block A: Aug 1987- July 1991; Block B Aug1991 - July1995 ; Block C Aug 1995-July1999; Block D Aug 1999-July 2003 and Block E Aug 2003-July 2007.

1950 (65\%) females had no addictions, while 900 (30\%) were addicted to tobacco and $150(5 \%)$ to betel nuts. None admitted that they consumed alcohol. But 2333 (77.77\%) admitted that their male partners were addicted to alcohol and/or smoking. Addiction is characterized by impaired control over use of the substance, preoccupation with the substance, use of the substance despite adverse consequences, and distortions in thinking. ${ }^{2}$

\section{Discussion}

Primary infertility has a higher prevalence as compared to secondary infertility in all the five blocks. The incidence of $350(11.69 \%)$ infertile cases in our study is slightly higher than that reported by Bovin (2007) with a prevalence of $9 \%$ infertile cases in developing countries.

Analysis of the cases in relation to the type of infertility and the age of the female has revealed that the prevalence of primary infertility is higher in all the age groups as compared to secondary infertility ( $\mathrm{P}$ value $<0.001)$. In the present study, the maximum of $1226(40.87 \%)$ cases presented to us in the age group of 26-30 years and was statistically significant ( $p<$ 0.001 ). Age of the youngest female was 19 years and the oldest female was of 40 years, the median age being 27.25. The higher prevalence in the age group of $26-30$ years could also be related to the age of marriage in our area which is between $21-25$ years and a waiting period of 2-3 years.

The social customs, traditions and the degree of freedom given by a particular religion or community attributes to the prevalence of infertility in that particular religion. ${ }^{4}$ In this study the number of Hindus presenting with infertility was more $1980(66 \%)$ compared with other sectors of the religious groups $1020(31 \%)$. This can be related to the fact that more Hindus were present in this set of population. Though an increasing trend can be seen in Hindus and Muslims, the reason for rate of infertility remaining constant in other religious sects needs to be explored. (Table 1)

The analysis of occupation of female cases showed that the majority $1800(60 \%)$ were farm workers, $720(24 \%)$ housewives and 480(16\%) were involved in sedentary jobs. Comparison of occupations of males also revealed higher prevalence of infertility in farm workers or laborers $1950(65 \%)$ as compared to $870(29.00 \%)$ in factory workers and $180(6 \%)$ in cases with sedentary jobs, which is statistically significant $(\mathrm{p}<0.001)$. Over the years, the prevalence of infertility was found to be increasing from $172(5.73 \%)$ in block A to $480(16 \%)$ in block $\mathrm{E}$ in female farmers or laborers and from 300 $(10 \%)$ in block A to $465(15.5 \%)$ in block E (Table 2 and 3 ).

A strong relationship between occupation of individuals and infertility is suggested in the previous studies. Greenlee et al (2003) had suggested that the agricultural occupation and exposure to pesticides may impair female fertility and mixing and applying herbicides 2 years before attempting conception may contribute to infertility. He also reported that employment in agriculture area increases the risk of specific morphological abnormalities in sperm including decreased sperm count per ejaculation and decline in percentage of viable sperms ${ }^{5}$. Hanke (2004) concluded that the exposure to pesticides and herbicides should be avoided in preconception periods. ${ }^{6}$ Exposure to excessive heat has a detrimental effect on testes and sperm production. Therefore, the high percentage of infertility in farm workers and factory workers can be due to the fact that they are chronically exposed to pesticides, herbicides, toxic metals and chemicals. Farmers have to careful while dealing with pesticides, wear protective gear and have minimum contact with it.

One of the earlier reports of correlation between strenuous exercise and infertility was by $\mathrm{Adam}^{7}$ et al. The women have to work hard the whole day in the fields which is a strenuous exercise and may contribute to infertility. Homan et al (2007) also acknowledged 
the relationship between various levels of exercise and reproductive performance. ${ }^{8}$ Studies examining the activity and adiposity levels affecting ovulatory disorder infertility are few. In a study by Rich-Edwards JW et al, an increase in vigorous activity (but not moderate activity) was associated with reduced relative risk of ovulatory infertility. Each hour per week of vigorous activity was associated with a $7 \%(95 \% \mathrm{CI}=4-10 \%)$ lower relative risk of ovulatory infertility. ${ }^{9}$ The farm workers or laborers also suffer from malnutrition which may affect reproductive functions. Risk of ovulatory infertility is highest in obese women but is also slightly increased in moderately overweight and underweight women. ${ }^{10}$ This might be a contributing factor for infertility in our observation as the women have poor diet and work very hard and so are underweight. But further research into this relationship is needed.

Table 4 on dietary habits reveals that $67.27 \%$ (2018 cases) are taking mixed diet and $32.73 \%$ (982) vegetarians. A relationship between dietary intake and infertility has been explored by some authors prior to this. Chavarro JE et al stated that consuming $5 \%$ of total energy intake as vegetable protein rather than as animal protein was associated with a more than $50 \%$ lower risk of ovulatory infertility ( $\mathrm{P}=0.007)$. Repla cing animal sources of protein with vegetable sources of protein may reduce ovulatory infertility risk. ${ }^{11} \mathrm{~A}$ combination of five or more low-risk lifestyle factors, including diet, weight control, and physical activity was associated with a $69 \%$ lower risk of ovulatory disorder infertility and an estimated population attributable risk of $66 \%$ (95\% confidence interval $29-86 \%) .{ }^{12}$ Balen and Jacobs (2003) extensively studied effect of diet on the reproductive function and concluded that it is unnecessary to take vitamin supplements as along as diet contains fresh fruits, vegetables, dairy products and fish. ${ }^{4}$ There is an inverse association between frequency of multivitamin use and ovulatory infertility. The multivariate-adjusted relative risk $(95 \%$ confidence interval) of ovulatory infertility is $0.88(0.60,1.28)$ for women consuming two tablets per week or less, 0.69 $(0.51,0.95)$ for women consuming three to five tablets per week, and $0.59(0.46,0.75)$ for women consuming six or more tablets per week, when compared with women who did not use these supplements ( $P$, trend $<.001$ ). Regular use of multivitamin supplements may decrease the risk of ovulatory infertility in those with inadequate intake. ${ }^{13}$

Folic acid appeared to explain part of the association between multivitamin supplement use and risk of ovulatory infertility. Folic acid if adequate in diet prevents neural tube defects and is also essential for proper implantation. Women who consumed iron supplements had a significantly lower risk of ovulatory infertility than women who did not use iron supplements (relative risk $0.60,95 \%$ confidence interval 0.39-0.92), after adjusting for potential confounders.
Consumption of iron supplements and nonheme iron from other sources may decrease the risk of ovulatory infertility. ${ }^{14}$ Khushalani (2001) reported that $78.18 \%$ conception occurred after treatment with folic acid and vitamin B6 in 55 cases of infertility, which is an encouraging report to understand the role of fresh fruits and vegetables. ${ }^{15}$ Trans unsaturated fats may increase the risk of ovulatory infertility when consumed instead of carbohydrates or unsaturated fats commonly found in nonhydrogenated vegetable oils. ${ }^{16}$

Drinking 3 or more glasses of milk per day was found protective for female fertility. ${ }^{5}$ Chavarro JE et al found that there is an inverse association between dairy fat intake and anovulatory infertility $(\mathrm{P}$, trend $=0.05)$. Intakes of lactose, calcium, phosphorus and vitamin D were unrelated to anovulatory infertility. High intake of low-fat dairy foods may increase the risk of anovulatory infertility whereas intake of high-fat dairy foods may decrease this risk. Further, lactose (the main carbohydrate in milk and dairy products) may not affect fertility within the usual range of intake levels in humans. ${ }^{17}$ Total carbohydrate intake and dietary glycemic load is also positively related to ovulatory infertility in analyses adjusted for age, body mass index, smoking, parity, physical activity, recency of contraception, total energy intake, protein intake and other dietary variables. An intake of fiber from different sources is unrelated to ovulatory infertility risk. ${ }^{18}$

Thus proper advice about diet and supplementation with vitamin B6, A and E and folic acid is needed in this rural population as the staple food in this rural area mainly consist of wheat, jawar, bajara, rice, brinjal and lack fresh fruits and vegetables .

$2220(74 \%)$ belonged to joint families and only $780(26.00 \%)$ belonged to nuclear families. The prevalence of infertility increased from 301(10.03\%) in block $\mathrm{A}$ to $560(18.67 \%)$ in block $\mathrm{E}$ in couples belonging to joint family (Table 5). This higher prevalence $(p<0.001)$ is statistically significant. Living in close knit families might deprive the couple of privacy leading to increased infertility.

In our study the majority of cases $62 \%$ (1860) cases belonged to lower socioeconomic group which is highly significant $(\mathrm{p}<0.001)$ when compared to the lower middle, middle, high middle and high socioeconomic group. This trend can be explained by the fact that most of them were involved in farming or work on daily wages and hence belonged to lower socioeconomic status. All the groups showed an increasing trend in seeking medical help for infertility over the last two decades (Graph1). This shows an increased awareness among all sectors of rural people.

As it is evident from the literature, infertility has been elevated by smoking. Greenlee ${ }^{5}$ et al, (2003) reported 
that smoking and passive smoking are the risk factors for female infertility and stated that the metabolites of cigarettes smoking are toxic to oocytes, sperm and embryos. Alcohol has profound effects on leydig cell function by reducing testosterone synthesis. Chronic alcoholism in men can cause testicular atrophy with decreased spermatogenesis or azoospermia secondary to endocrinological consequences of hepatic compromise. Men with oligospermia should be counseled to reduce the amount they drink or to stop drinking altogether. In our study only $35 \%$ ( 1050) of the females were addicted to tobacco and they admitted that $77.77 \%$ ( 2333) of the male partners were smokers and alcoholics. This suggests that smoking and alcohol may play a part in infertility and modification of this risk factor might be necessary.

\section{Conclusion}

This study provides a quantitative estimate of the prevalence and lifestyle risk factors for infertility in Indian rural couples. Infertile couples seeking medical interventions often disregard lifestyle factors which have adverse effects on fertility as they are not aware of them. Clearly there is a need for early education on value of lifestyle practices in relation to management of infertility. The physician must also be aware of link between lifestyle and development of impaired fertility.

Educating couples about modifiable risk factors like age at conceiving, working habits, dietary habits and addictions can be advantageous in the prevention of infertility. Yet further studies on the cause of primary and secondary infertility and geographical variations in the incidence and prevalence of infertility in Indian rural couples are needed to prove the above risk factors beyond any doubt.

\section{References}

1. Chang WY, Agarwal SK and Azziz R. Diagnostic evaluation and treatment of the infertile couple. Carr BR, Blackwell RE, Azziz R (eds). Essential Reproductive Medicine, Tata McGraw-Hill Ediction, New Delhi 2005; 359-392.

2. Morse RM; Flavin DK (1992). "The definition of alcoholism. The Joint Committee of the National Council on Alcoholism and Drug Dependence and the American Society of Addiction Medicine to Study the Definition and Criteria for the Diagnosis of Alcoholism". JAMA 268 (8): 10124. Retrieved on 2008-06-29.

3. Boivin J, Bunting L, Collins JA, Nygren KG. International estimates of infertility prevalence and treatment seeking: potential need and demand for infertility medical care; Hum Reprod. 2007 Jun; 22(6):1506-12

4. Balen AH, Jacobs H. Planning a pregnancy Infertility in practice $2^{\text {nd }}$ ed. Churchill Livingstone
Edinburgh, 2003; 27-50.

5. Greenlee AR, Arbuckle TE, Chyou PH. Risk factors for female infertility in an agricultural region. Epidemiology, 2003; 4: 429-436.

6. Hanke W, Jurewiez J. The risk of adverse reproductive and developmental disorders due to occupational pesticide exposure: an overview of current epidemiological evidence. Int Occup Med Environ Health 2004; 17 (2); 223-243.

7. Adams J, Franks S, Polson DW et al. Multifollicular ovaries: clinical and endocrine features and response to pulsatile gonadotropinreleasing hormone. Lancet 1985; 2: 1275-1278.

8. Homan GF, Davies M, Norman R. The impact of lifestyle factors on reproductive performance in the general population and those undergoing infertility treatment: a review. Hum Reprod Update. 2007 May- Jun;13(3):209-23.

9. Rich-Edwards JW, Spiegelman D, Garland M, Hertzmark E, Hunter DJ, Colditz GA et al. Physical activity, body mass index, and ovulatory disorder infertility. Epidemiology. 2002 Mar;13(2):184-90.

10. Grodstein F, Goldman MB, Cramer DW. Body mass index and ovulatory infertility. Epidemiology. 1994 Mar;5(2):247-50.

11. Chavarro JE, Rich-Edwards JW, Rosner BA, Willett WC. Protein intake and ovulatory infertility. Am J Obstet Gynecol. 2008 Feb;198(2):210.e1-7

12. Chavarro JE, Rich-Edwards JW, Rosner BA, Willett WC. Diet and lifestyle in the prevention of ovulatory disorder infertility. Obstet Gynecol. 2007 Nov;110(5):1050-8.

13. Chavarro JE, Rich-Edwards JW, Rosner BA, Willett WC. Use of multivitamins, intake of B vitamins, and risk of ovulatory infertility. Fertil Steril. 2008 Mar;89(3):668-76. Epub 2007 Jul 10.

14. Chavarro JE, Rich-Edwards JW, Rosner $\mathrm{BA}$, Willett WC. Iron intake and risk of ovulatory infertility. Obstet Gynecol. 2006 Nov;108(5):1145-52 .

15. Khushalani K, Bansal P. Role of folic acid and vitamin B6 in the treatment of infertility of infertility. Obstet and Gynae, 2001; VI (1): 23-25.

16. Chavarro JE, Rich-Edwards JW, Rosner BA, Willett WC. Dietary fatty acid intakes and the risk of ovulatory infertility. Am J Clin Nutr. 2007 Jan;85(1):231-7

17. Chavarro JE, Rich-Edwards JW, Rosner B, Willett WC. Prospective study of dairy foods intake and anovulatory infertility. Hum Reprod. 2007 May;22(5):1340-7. Epub 2007 Feb 28.

18. Chavarro JE, Rich-Edwards JW, Rosner BA, Willett WC. A prospective study of dietary carbohydrate quantity and quality in relation to risk of ovulatory infertility. Eur J Clin Nutr. 2007 Sep 19. 